\title{
A Student-Centred Writing Curriculum
}

Deborah Gibson

This paper presents a design for a flexible curriculum for a writing class which meets the problem of varied student levels and goals by basing the course curriculum and content on the students' own written work. Whole class, small group, and individual student pre-writing and follow-up activities are described.

\section{RATIONALE}

Teachers of adult non-credit writing courses often encounter major problems with a fixed course curriculum due to varied student needs, goals and abilities. There may be students in the class who, at the end of a three-month course (eight hours per week), want to continue to study writing but do not wish to repeat the curriculum. At the same time, the bulk of the class consists of students taking the course for the first time. Some students might even register in a course of this kind for three sessions running. To complicate matters, the student population may be very mixed in other ways, varying from lower intermediate proficiency to very advanced, and including both those bound for English-speaking universities (with or without degrees from their countries) and those taking the course for general language improvement. Of course, there may also be students who love to write and students who do not.

One solution to the variations in the adult non-credit course is to base the course curriculum and content on the students' own written work. Techniques, including the use of worksheet handouts produced by the instructor from items taken from student compositions, allow the needs of a multi-level class to be met. At the same time, students are not subjected to repeated material from one course to the next.

The standard components of a grammar-based or functional composition curriculum, i.e., organization, vocabulary improvement, sentence structure and combining, verb tense sequence and transitional words are addressed in each course, as students' needs are predictably within these general areas. Components of the curriculum are not taught merely in a step-by-step, once-only fashion, but are constantly re-introduced in a circular mode using the worksheet handouts generated during each specific assignment. At various stages during each assignment, peer critiqu- 
ing techniques encourage students to write for an audience other than the teacher, thereby inspiring more careful work and even clearer handwriting.

The course consists of a series of expository and descriptive composition assignments based on topics chosen in part from those the class has expressed an interest in. In each three-month session, students work towards the production of a book of their favorite compositions. The final product is complete with addresses of class members and an autograph page. This "course anthology" consists of compositions rewritten to the point where they are publishable.

Each course assignment follows a series of steps:

- pre-writing activities

- first draft

- peer critiques

- instructor feedback on first draft

- worksheet handouts combined with textbook exercises

- second draft

- peer critiquing

Students keep all drafts. Two or three times during the course, they meet with the instructor for a one-to-one analysis of their work. These stages are described in more detail below.

\section{PRE-WRITING ACTIVITIES}

Initially, students are provided with stimulating pre-writing experiences that generate ideas for writing. The entire class participates in the experience, although the interpretation of each is left up to the individual. A field trip provides the stimulus for descriptive writing and for expository writing. Other techniques for generating ideas for expository compositions may include a combination of brainstorming on a topic of interest, watching videos or student-produced slide shows, and reading newspaper and magazine articles.

The following pre-trip handout illustrates how students can be provided with guidelines for developing descriptions. In this case, the handout was used for visits to various points around the scenic University of British Columbia peninsula.

\section{Handout \#1: Field Trip-The Viewpoint}

Descriptions to consider:

1. Spatial relationships: totem poles water 
cliff

beach

mountains

Georgia Strait

any boats, ships, tugs or barges

the horizon

2. Sensations:

sound

wind

temperature

colours

movement

memories

feelings

images

While on a field trip, students make point-form notes (often using vocabulary which they request as needed from the instructor). After some five to ten minutes of note-taking, students are asked to compare notes. Although this activity sometimes leads to translation, this tendency generally becomes less of a problem over time.

The instructor also takes notes which are copied and distributed to students back in the classroom. One drawback of using such a handout is that some students rely too heavily on handout vocabulary when composing their own essays. A short sample of such notes follows.

\section{Handout \#2: The Viewpoint}

distant islands to the west

encircling mountains, blue horizon

small fluffy clouds

small white-caps

soft warm breeze

an occasional cruiser

serene place/contrasting sign "danger/cliffs/keep away"

\section{FIRST DRAFT}

The students write their first draft of the field trip description either for homework or in class the next day. Drafts are then subjected to a peer critiquing session.

\section{PEER CRITIQUES}

Using Handout \#3, the first drafts are then corrected by peers who STUDENT-CENTRED WRITING 
examine compositions in terms of their organization, content, clarity and style, but not grammar errors. Typically, students work in pairs or groups of three. They read each other's work and then fill in a Critic's Sheet to help their colleagues rewrite the first draft. Critic's Sheets should provide as many opportunities for praise as for negative criticism. A typical Critic's Sheet for a field trip follows:

\section{Handout \#3: Critic's Sheet}

\section{WRITER —}

CRITIC

1. List the verb vocabulary. Don't include 'be', 'have', 'do', 'make' or 'get' used as main verbs.

2. Spatial organization:

3. List all expressions describing spatial relationships.

4. List analogies and metaphors.

5. Overall feeling, response to the subject:

6. Are there enough details? ok yes - not mentioned

When the students have completed these sheets for each other, they return them to the writer, who then decides if any revision is necessary before handing in the draft. On the handout above, an absence of listed verbs should indicate to the writer that his verb vocabulary is deficient for descriptive prose, while an absence of metaphors can result in a less expressive style. Of course, there is the danger that the critic may be too severe or too forgiving, or that the writer may disagree with an excellent critic. However, the Critic's Sheets also focus the writers' attention on their own work, and provide both a larger reading audience and an interactive component in the classroom.

\section{INSTRUCTOR FEEDBACK ON FIRST DRAFT}

If students feel that a rewrite is necessary after hearing their peers' critiques, they work on the first draft and then submit it to the instructor. The instructor then checks papers, paying particular attention to the following: organization, clarity, vocabulary choice, grammatical competence. Errors are indicated using copy-editing symbols, but they are generally not corrected except in the case of some idiom or vocabulary choices. This handout contains examples of typical writing errors.

\section{Handout \#4: Symbols for Error Indication}

These symbols indicate the type of error you have made. 


$\begin{array}{ll}\text { AGT } & \text { agreement of subject and verb } \\ \text { T } & \text { verb tense } \\ \text { A/P } & \text { active/passive mood } \\ \text { PREP } & \text { preposition } \\ \text { ART } & \text { article } \\ \text { F } & \text { word form } \\ \text { (WO) } & \text { word order } \\ \text { SS } & \text { sentence structure } \\ \text { V } & \text { vocabulary } \\ ? & \text { unclear } \\ \text { SP } & \text { spelling } \\ \text { (RO) } & \text { run-on sentence, comma splice } \\ \text { TR } & \text { transition words, links, conjunctions } \\ \text { FRAG } & \text { sentence fragment } \\ \text { P } & \text { punctuation } \\ \text { A } & \text { omission } \\ \text { C } & \text { combine these sentences }\end{array}$

\section{WORKSHEET HANDOUTS}

While the first drafts are still with the teacher, classroom work on the assignment continues. This work is based on needs specific to the assignment in progress. In the field trip composition, for example, there was a need for spatial vocabulary including prepositions such as "beneath", and expressions such as "on the right side of" and "to the right of". Handout \#5 is an abbreviated example of a worksheet used to teach spatial expressions related to one assignment.

\section{Handout \#5: Spatial Descriptions}

Correct the underlined phrases where necessary.

1. West inside UBC is the Anthropology Museum.

2. The seascape, from the hill that is located in front of the Anthropology Museum, was very beautiful.

3. Vancouver Island is located to the west of Vancouver separate by Georgia Strait to the West Vancouver is Bowen Island, and Burrard Inlet in between of North Vancouver and Vancouver.

The Critic's Sheet only required students to identify these structures in the work of one or two other students, but not to correct them. whereas the handout above would contain all examples of space descriptions used by the class, both correct and incorrect. Small groups in class argue the merits of each underlined phrase, and then do a class check of the answers. 
Descriptive writing calls for a knowledge of analogies and metaphors. Initially, students are encouraged to identify these using their Critic's Sheet to record examples from their colleagues' drafts. Another worksheet handout used during this stage consists of all the uses and misuses of metaphors found in student drafts for the assignment under study. The field trip theme mentioned earlier gave rise to expressions such as "looks", "looks like", "looks as if", "feels like", etcetera. Being exposed to samples from the whole class also assisted students in identifying metaphors. Student names are included beside examples of metaphors, as this allows recognition of "good writing". Any errors on this handout are indicated using the copy editing symbols from Handout \#4.

\section{Handout \#6: Analogies and Metaphors}

1. It looked like a Japanese painting in black and white. (Satoko)

2. When I saw seagulls ${ }^{\wedge}$ TR were flying above the surface, I feel $T$ like became $\mathrm{T}$ a bird. (Masamitsu)

3. The panoramas were as beautiful as if these were air-brushing $\mathrm{F}$ paintings. (Fabiola)

4. The mountains were snow-caps F. (Federico)

5. Seagulls were flying over the boats like $V$ freighter $F$. (Jaemin)

6. Spring has come and every trees $\bar{F}$, grasses $\bar{F}$, and mountains $F$ look like SS lively. (Chako)

7. The misty horizon made me remind SS PREP my hometown and ${ }^{\wedge} \mathrm{SS}$ feel $\mathrm{T}$ as if I were to stand $\mathrm{F}$ in my home's yard F. (Eom)

\section{FINISH THESE SENTENCES:}

1. The view made me feel . . . . . . . . .

2. The mountains looked ..........

As students often seem to have much larger noun and adjective vocabulary, another natural class follow-up to the Critic's Sheet is a lesson on verb vocabulary. Using either the student-compiled Critic's Sheets or good descriptive verbs from a reading of their work, the following handout is prepared by the instructor in order to teach verb vocabulary, tenses, and active/passive mood. Again, students' names could be added to their examples. Students having problems with the tense and mood part of this handout are given supplementary textbook exercises.

\section{Handout \#7: Good Verbs}

For the verbs below, find a synonym, identify the tense, and indicate which verbs are passive. 
1. we approached

2. it was clouded

3. I observed

4. ships were drifting

5. the water was undulating

6. totem poles which symbolized

7. a barge was gliding

8. the cliff had been eaten away.

9. the wall of the cliff was composed of

General vocabulary improvement is always a possible follow-up to any writing activity, whether descriptive or expository. In place of the "Good Verbs" handout, one based on the students' use of "good" vocabulary items could have been used. Such a handout could be put together by the students themselves after reading each other's work. It should be noted that students with a large vocabulary may sometimes leave out items which others may not know; similarly, students with a small vocabulary may include very common words. On the other hand, the instructor could compile the list of words from readings of student compositions. Such a handout could look like the following which was based on a different field trip from the preceding example. Mistakes in word forms found in assignments are asterisked, but not corrected.

\section{Handout \#8: East Canyon Trail Vocabulary Sheet}

Find the meanings of the words below by asking the authors mentioned. Identify all possible verbs, whether or not they were used as verbs by the authors.

$\begin{array}{lll}\text { GUY-ANNE } & \text { PETER } & \text { YOK } \\ \text { intimacy } & \text { peninsula } & \text { improvised } \\ \text { integrated* } & \begin{array}{l}\text { primitive } \\ \text { arduous* } \\ \text { novice }\end{array} & \begin{array}{l}\text { penetrate } \\ \text { predominated* }\end{array} \\ \text { blissful } & \text { rustle } & \text { canopy } \\ \text { mourning } & \text { woodpecker } & \text { monotony } \\ \text { gigantic } & \text { fluttered } \\ \text { overwhelming } & \text { SHUKO } & \text { perils } \\ \text { immensity } & \text { muddy* } & \text { stumbled } \\ \text { simultaneously } & \text { hardships } & \text { abruptly } \\ \text { sprawled } & \text { mouldy } \\ \text { landscape } & \text { swsks } & \\ & \text { swampy } & \end{array}$

The time spent in class on this exercise is normally limited to twenty minutes to avoid overloading students' memories with new words. 
Again, verbs are identified to increase verb vocabulary. Another possibility is to ask students to find all related words: e.g. intimacy, intimate; integrated, integration. Having the author of each list supply the meanings requires knowing how to pronounce the words, so an introductory step is to have writers read their lists aloud, and have the rest of the class repeat. This also increases the number of exposures to each vocabulary item, thereby facilitating acquisition. Occasionally, the class is asked to supply ten new words from a vocabulary sheet and then these are put on the board. Next students are asked to write as short a story as possible containing all ten words. These often humorous stories can then be passed around to be read silently or read aloud by each student.

Like the vocabulary handout above, the following handouts (\#9 and \#10) can be used with descriptive or expository prose samples. After each first draft has been handed in, but before it is returned, a handout of typical grammar errors is prepared. The handout consists of one sentence from each student's essay, with errors indicated by the copywriting symbols on handout \#4.

Working in small groups, the students correct errors, after which different versions (there is usually more than one possible correction) are put on the board and analyzed for correctness, style and the inclusion of all necessary information. As this handout can be fairly long, it is often worked on for half an hour a class over two or three periods. This grammar work is interactive, not only because students are in small groups, but because the author is frequently appealed to (if he/she doesn't wish to maintain anonymity) for clarifications of meaning. In addition, students can consult with native speakers of English to provide valuable help with handout questions completed as homework. In the following handout example, the content of the assignment produced many adverb clauses. Grammar handouts, however, generally contain a wider variety of errors including sentence combining, sentence fragments and run-on sentences.

\section{Handout \#9: Grammar Errors-Adverb Clauses}

In small groups, correct all errors shown and identify adverb clauses.

1. Last week $I$ went to the East Canyon trail because one of my best friends told me about the beautifuly $\mathrm{F}$ experance SP that he has $\mathrm{T}$ in that place.

2. ( ${ }^{\wedge}$ East Canyon field trip it was) SS a good experience for me because I saw a lot of things.

3. Last Wednesday, as the weather was very clear, we had $\mathrm{V}$ a walk at PREP East Canyon trail.

4. (At first 1 entered East Canyon Trail) SS, (where was ${ }^{\wedge}$ big rain forest) SS, I felt so cold. 
5. (It was a big surprise for me that I could see) SS such a natural rain forest near a city, because hardly any rain forest has been remained $\mathrm{A} / \mathrm{P}$ in Korea.

To some degree, all choices of error symbols are arbitrary. In sentence five, for example, the error symbol A/P could as easily have been V. This would have resulted in the correction, "has been kept" rather than "has, remained". Because students find that being exposed to several different ways of expressing an idea is very informative, this is one of the reasons for having each group put its corrected version on the board.

In working through the grammar errors, two other points are worth noting. In selecting sentences for correction, the instructor considers the proficiency of the author. In sentence five of Handout \#9, for example, the SS symbol refers to wordiness and the use of unidiomatic English. Technically, however, the sentence is not wrong. If a less advanced student had written it, there may have been no need to ask for any change. It is also important that the focus on errors may give rise to initial embarassment, in spite of the fact that a sentence from each student's work is included. For this reason, either on the handout or in class, something positive about each sentence is pointed out. Comments may refer to length, complexity, vocabulary, sentiment, or humour.

In any sort of composition, introductions and conclusions merit attention. Using the students' own work, these can be taught in several ways. Before the students have actually handed in their first draft, for example, the instructor might have students write down their first and last sentences on a blank piece of paper. These are then copied and redistributed to the class which chooses its favourites and prepares to justify the choice. Another method is to prepare a handout of the instructor's choices and have the students guess at the reasons for the selection. These may include the use of attention-getters which state the topic to introduce an essay, or summaries of the content, projections for the future, humour or expressiveness used to conclude the essay.

\section{Handout \#10: Excellent Introductions and Conclusions and Introductions}

Combine sentences where necessary.

\section{Introductions}

1. If you go to some beautiful viewpoints at UBC, you will find yourself in your dream.

2. I would like to convey you to a beautiful viewpoint which is located behind the Anthropology Museum. 
3. We had a field trip in the writing class under the lovely sun. I had a lot of sensations on this field trip. I will try to express some of the strongest impressions.

\section{Conclusions}

1. This will remain in my memory as a wonderful field trip.

2. I'd like to visit there again with my boyfriend or when I have died of a broken heart.

3. If you want to melt into the silence, you should go there. Maybe you will be content.

Organizational techniques in longer compositions can be taught, not by a handout, but by having the students prepare a post-outline after the first draft. They can do this for their own work or for another student. Each paragraph is numbered and a brief description of its contents is listed. In this way overlappings, repetitions, omissions and other organizational flaws become apparent. The rewrites often become longer.

It is worth noting that although all of the handouts in this paper have used examples from various field trips, these have been drawn from several courses. It is not advisable to use many handouts from a single composition, but rather to do a couple of handouts from each composition assignment to avoid boredom.

\section{SECOND DRAFT}

After the students' papers have been checked (no grades are assigned as these are non-credit courses), the papers are returned and students begin their rewriting, which includes not only correcting grammar errors, but making changes that may have been suggested on the handouts (e.g. organizational changes, vocabulary and style improvement). All changes are underlined before being handed back in. A lot of class time is given to writing and rewriting, while the handouts and supplementary exercises are homework. Usually a next pre-writing activity has started before all the students have finished rewriting. Students are given the choice at this point of working alone, with a partner of their choice, or in groups. As they become more comfortable with peer critiquing, they become more eager to read each other's work and to have an audience for their own.

\section{SECOND DRAFT AND FOLLOW-UP ACTIVITIES}

After their rewritten papers have been checked again (at this point 
any problems are corrected rather than indicated with symbols), students rewrite only those parts which need changing, unless they've chosen the composition for publication in our book, where a perfect copy is required. Some of these corrected papers are xeroxed for reading by the whole class or by small groups. Usually it is helpful for a student to read the paper aloud while the others follow by reading the copy. Encouraged by the teacher's asking for what is "good" in each paper, the class quickly becomes generous in spontaneous praise, recognizing improvement in the less advanced and granting recognition to the better writers.

Peer critiquing leads to an increased ability to self-critique, and the interactive methods make the classroom a more warm and friendly place, with the students expressing an appreciation for each other's work. Having a wider audience for written work also motivates students to produce good work, an important consideration in an ungraded course. On the last day, when the students are busy autographing each other's books (published on our copying machine and decorated by the class artist with photographs from the field trips), a real sense of accomplishment is felt.

\section{THE AUTHOR}

Deborah Gibson has been an instructor of visa students at the Language Institute, UBC, since 1976. She has also taught in the Department of Language Education and the Department of Linguistics at UBC, and has an M.A. in Linguistics from the same university. Her experience includes teaching ESL in programs for adult immigrants, francophone Canadian students, ESL teacher training, and research in language-disordered children. 